\title{
Experimental Examination on the Cooling of a Helmet using Microencapsulated Phase Change Material
}

\author{
K. Vijayrakesh, S. Muthuvel
}

\begin{abstract}
A helmet is the important personal protective equipment for the motorcyclist. This work analyses the use of the microencapsulated phase change material (MPCM) to cool the helmet and also investigate the effect of the inside heat generation rate, simulated radiation and wind speed on the cooling systems. The results indicate that with MPCM packed helmet has the ability to sustain constant temperature for more time when compared to the normal helmet. The findings also show that the head heat generation rate is the main factor that will affect the cooling time of the system. The wind speed and simulated radiation did not affect much on the cooling time. The results depicted that the extension of the helmet cooling time is based on the amount of MPCM embedded inside the helmet. Even though this investigation concentrates on cooling of helmet, the findings would also be helpful for the improvement of MPCM in many other applications.
\end{abstract}

Keywords: Microencapsulated phase change materials, helmet cooling, thermal comfort

\section{INTRODUCTION}

Phase change material (PCM) are selected as the best choice for the thermal energy storage because of high thermal energy storage density due to their high latent heat of fusion [1]. PCM can store and release thermal energy at an almost constant temperature, near the operating temperature range of many commercial applications like heating and cooling of buildings and solar energy systems [2]. However, PCM have a limitation in low thermal conductivity and as the PCM melts the liquid phase creates problems like leakage [3]. Microencapsulation helps to overcome low thermal conductivity by increasing the surface to volume ratio and the leakage issue also solved by containing the melted PCM inside micro sized capsule made upof material with a higher melting point than PCM [3]. The most common methods for preparation of microencapsulated phase change materials (MPCM) are interfacial polymerization, suspension polymerization, coacervation, emulsion polymerization and spray drying [4].

MPCM is one the well-known and advanced materials for better applications in building parts such as walls, floors and within the building materials [5].

Revised Manuscript Received on December 15, 2019.

* Correspondence Author
K. Vijayrakesh*, Assistant Professor,
$\begin{aligned} & \text { Engineering,Kalasalingam Academy of Research and } \\ & \text { Virudhunagar, India. Email: k.Vijayrakesh@klu.ac.in }\end{aligned}$
S. Muthunel,
$\begin{aligned} & \text { Engineering,Kalasalingam } \\ & \text { Virudhunagar, India. Email: s.muthuvel@klu.ac.in }\end{aligned}$

MPCM have been proved to be excellent in moderating the temperatures of electronic components, photovoltaic modules and power batteries [6]. The present study analyses the MPCM usage for the thermal comfort of motorcycle helmet as it is an essential piece of safety equipment for the motorcyclist. Personal protective equipment with uncomforted manner can affect performanceand create hazard that could leads to accidents [7]. The main factor affects the rider is dependent of temperature and the comfortable temperature for head is around $37^{\circ} \mathrm{C}$ [ 8]. During the hot climatic conditions, the temperature inside the helmet could reach $50^{\circ} \mathrm{C}$ under sunny weather with the absence of wind [9]. Because of these high temperatures inside the helmet rider can be affected by hypothermia [10]. To prevent this problem, it is essential to maintain the temperature inside the helmet to around the comfortable temperature $38^{\circ} \mathrm{C}$ [11]. The MPCM used in present study is 1-tetradecanol which has melting point around $36.65^{\circ} \mathrm{C}$ [12] which is suitable for the helmet applications. Fok et al [13] studied their experimental investigation on the cooling of a motorcycle helmet with PCM n-octadecane which has melting point around $30^{\circ} \mathrm{C}$ and concluded that the PCM embedded helmet take a longer time to exceed the thermal comfort zone compared to the normal helmet and head heat generation was the main factor which shorten the cooling time. The MPCM cooled helmet provide the thermal comfort for about $2 \mathrm{hrs}$ and the usage of MPCM cooled can be increased with the usage of MPCM with higher heat storage [14].

\section{EXPERIMENTAL DESIGN, SETUP AND TESTING}

The helmet installed with the small pouch of MPCM called phase change materials storage unit (PCMSU) and placed inside the wind tunnel for the experimental investigation purpose. The black colour standard half face helmet is studied as it so absorbs more heat when compared to white colour helmet. The PCMSU is fitted inside the helmet as shown in figure 1 . 


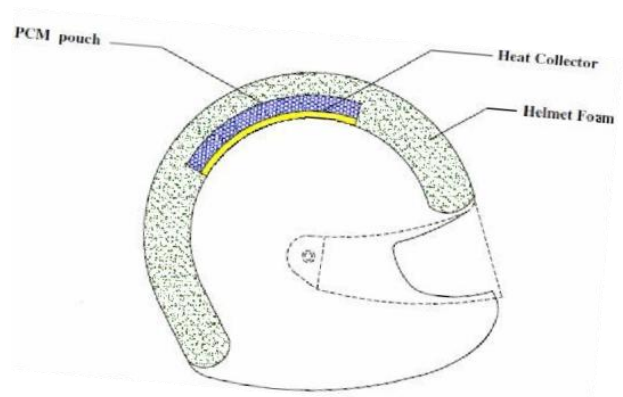

Fig 1. MPCM embedded helmet

TABLE 1. THERMAL PROPERTIES OF PCM

\begin{tabular}{|l|l|}
\hline \multicolumn{1}{|c|}{ Description } & \multicolumn{1}{c|}{ Value } \\
\hline Melting point & $37^{\circ} \mathrm{C}$ \\
\hline Density & $824 \mathrm{~kg} / \mathrm{m}^{3}$ \\
\hline Latent heat & $265500 \mathrm{~J} / \mathrm{kg}$ \\
\hline Thermal conductivity & $0.54 \mathrm{~W} / \mathrm{mK}$ \\
\hline Specific heat capacity & $2230 \mathrm{~J} / \mathrm{kgK}$ \\
\hline
\end{tabular}

The PCMSU is fitted only at the top of the helmet which receives the solar radiation directly from the sun and studied for the cooling performance with the help of MPCM. The PCMSU has the storage capacity of $20 \mathrm{~g}$ of solid 1tetradecanol. The nichrome wire resistance heater is used as the heater which is held at the bottom of the PCMSU for the simulation of heat generated from the head and the generated heat is regulated by the AC power supply. The leakage of MPCM is prevented by using the rubber gasket and in addition to that all gaps are sealed with epoxy glue. The PCMSU is replaceable with the help zip type opening provided inside the helmet. The experimental investigation is studied with the help of the wind tunnel as shown in figure 2

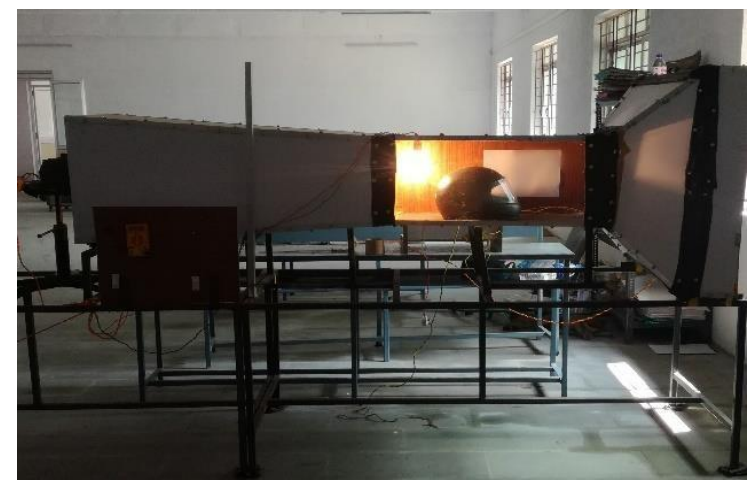

Fig 2. Experiment set up

The helmet is placed inside the test section of wind tunnel and to prevent any movement or vibration the helmet is tightly fitted with the help of bolts and nuts. The ceramic 250 $\mathrm{W}$ bulb is used to simulate the solar radiation and it is mounted at the roof of the test section of the wind tunnel at downstream angle of $45^{\circ}$ which is focused on the top of the helmet where the MPCM is held. The outer surface temperature of the helmet is raise from ambient temperature $30^{\circ} \mathrm{C}$ to $60^{\circ} \mathrm{C}-70^{\circ} \mathrm{C}$ by adjusting the horizontal distance between the bulb and helmet without the absence of wind. At the surface of the helmet the heat flux reaches would be 198
$\mathrm{W} / \mathrm{cm} 2[9]$. The temperature for test conditions is measured using the infrared thermometer by wearing the helmet in a 45 ${ }^{\circ} \mathrm{C}$ sunny day in India. The ram air generated during the vehicle motion is simulate with the help of wind tunnel. The wind speed in the wind tunnel is adjusted by the regulator connected with electrical exhaust fan in the wind tunnel. The wind speed is measured using digital anemometer.

Four strategically placed k-type thermocouples are used to measure the average helmet interior temperature. The temperature on the helmet surface is measured using the infrared thermometer. One thermocouple is placed on the heater. All the thermocouples are calibrated and measured. The effectiveness of MPCM cooling solution is the main parameter to be investigated in this study. The wind speed, solar radiation and the heater power are the parameters which affect the cooling of MPCM.

\section{RESULTS AND DISCUSSION}

\section{A. MPCM EFFECT ON HELMET INTERIOR TEMPERATURE}

Figure 3 compares the PCMSU temperature vs. time results between the normal and PCM-cooled helmet subjected to a constant heater power at $6 \mathrm{~W}$ with no wind and the radiator heater switched off. Without PCM, it took about 5 minutes for the temperature to reach $40^{\circ} \mathrm{C}$. Adding $20 \mathrm{~g}$ of MPCM extends the time to about 27 minutes. The results show that with the use of MPCM, the temperature inside the helmet can be maintained at a lower temperature for a longer period of time. The amount of MPCM used in the experiment had not been optimized to prolong the cooling time. It is envisaged that the cooling period could be extended by using more MPCM. However, more MPCM would also increase the weight of the helmet.

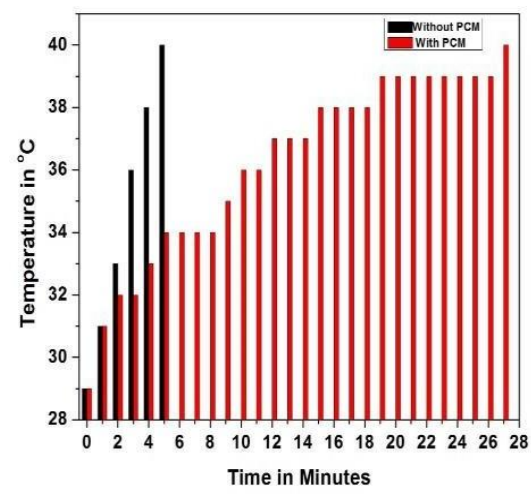

Fig 3. Helmet interior temperature vs time -with and without MPCM subjected to heater power.

\section{B. MPCM EFFECT ON SIMULATED RADIATION}

Figure 4 shows the effect of the simulated radiation on the PCMSU temperature vs. time profiles with no wind and the heater at $6 \mathrm{~W}$. Without MPCM, it took about 5 minutes for the temperature to reach $40^{\circ} \mathrm{C}$ and with MPCM and simulated solar radiation it takes about 20 minutes respectively.

Although the MPCM cooling time with simulated solar radiation is slightly shorter than without simulated radiation, the difference is small. This could be attributed to the helmet design. The design of helmet contains three main layers namely the outer shell, impact

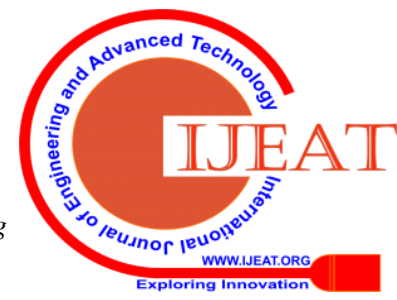


absorbing-liner, and comfort padding.

The outer shell is made up of plastics. Some of the plastics offer very good protection from penetration as in lexan (bulletproof glass) but will not crush on impact, so the outer shell will look undamaged and offering better protection. The impact absorbing-liner is made up of Expanded Polystyrene foam and it acts as a cushion to reduce the force during accidents. This layer thickness is about 2 to $4 \mathrm{~cm}$ and it act as the thermal insulating agent. The comfort padding is used for comfortable contact between the helmet and head. All these three layers offer the insulation to reduce the heat gained from the radiation. As such, the effect of radiation on the MPCM cooling time is not significant.

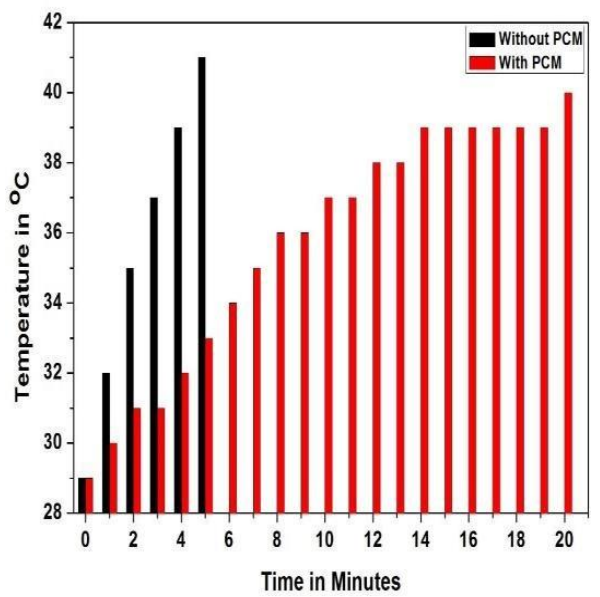

Fig 4. Helmet interior temperature vs time- with and without MPCM subjected to simulated radiation.

\section{c. MPCM EFFECT ON SIMULATED RADIATION AND WIND SPEED}

Figure 5 shows PCMSU temperature vs. time profiles for radiation and wind speed and the heater at $6 \mathrm{~W}$ with and without MPCM. Without MPCM it takes 5 minutes to $40^{\circ} \mathrm{C}$ and without MPCM it takes around 29 minutes. The MPCM cooling time rises 2 minutes for wind speed. This again can be described to the helmet design. Less amount of heat conducted across the head due the insulation provides in helmet. Forced convection is used on the outer surface to remove the heat within the helmet will not be effective and the wind speed would have very little effect on the MPCM cooling time.

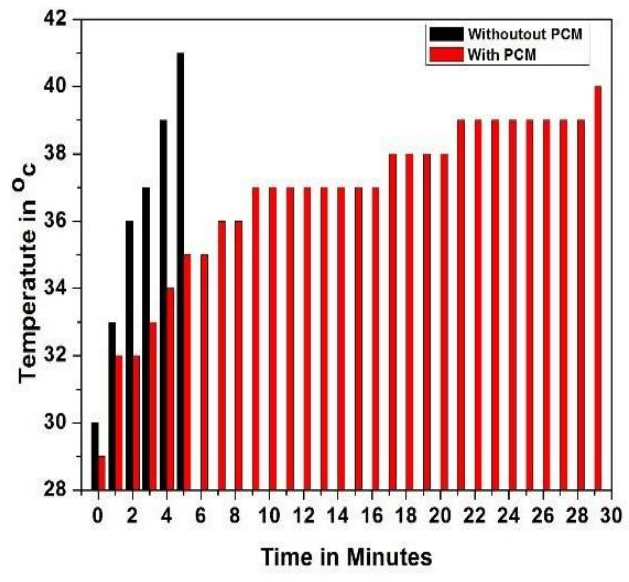

Fig 5. Helmet interior temperature vs time- with and without MPCM subjected to simulated radiation and wind speed.

\section{MPCM EFFECT ON HELMET INTERIOR TEMPERATURE AND WIND SPEED}

Figure 6 shows PCMSU temperature vs. time profiles for wind speed and the heater at $6 \mathrm{~W}$ with and without MPCM. Without MPCM it takes 6 minutes to $40^{\circ} \mathrm{C}$ and without MPCM it takes around 33 minutes. The MPCM cooling time increases for wind speed without radiation. For the night time riders this condition is tested. This again can be described the helmet design. Less amount of heat is conducted across the helmet due to the insulation provided by the three layers mentioned in the previous subsection. Forced convection is used on the outer surface to remove the heat within the helmet will not be effective and the wind speed would have very little effect on the cooling time of the helmet.

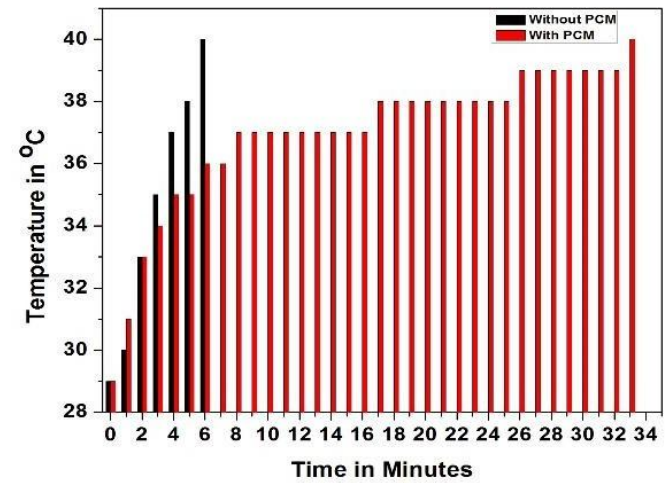

Fig 6. Helmet interior temperature vs time- with and without MPCM subjected to heater power and wind speed.

\section{CONCLUSION}

MPCM effect on the helmet interior temperature subjected to the heater power of $6 \mathrm{~W}$, simulated radiation of $250 \mathrm{~W}$ and wind speed of $40 \mathrm{kmhr}-1$ upon a helmet have been investigated. The results showed that using MPCM-cooling system, the temperature inside the helmet takes more than 6 time to extend the thermal comfort zone compared to a normal helmet. The result also shows that higher heat generation rate was the main factor that shorten the MPCM cooling time. Simulated radiation and wind speeds do not have much impact on MPCM cooling system. For real time purposes, the amount of MPCM used has to be increased so that the cooling period can be extended. Suggestions based on health and safety advised that motorcyclist should take rest at least once every two hours during long drive. As such, the MPCM should be capable of providing continuous cooling for up to two hours. Even though the investigation focuses on the cooling of a motorcyclist helmet, the findings could also be useful for the development of passive cooling system in many more applications.

\section{REFERENCES}

1. GSharma, A., Tyagi, V. V., Chen, C. R., \& Buddhi, D. (2009). Review on thermal energy storage with phase change materials and applications. Renewable and Sustainable energy reviews, 13(2), 318-345.

2. Farid, M. M., Khudhair, A. M. Razack, S. A. K., \& Al-Hallaj, S. (2004). A review on phase change

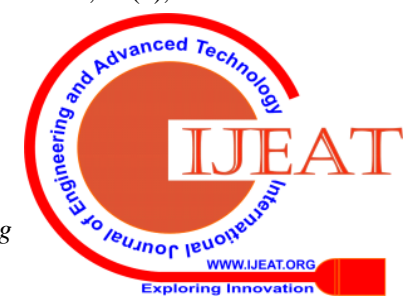


energy storage: materials and applications. Energy conversion and management, 45(9-10), 1597-1615.

3. Alva, G., Lin, Y., Liu, L., \& Fang, G. (2017). Synthesis, characterization and applications of microencapsulated phase change materials in thermal energy storage: a review. Energy and Buildings, 144, 276-294.

4. Jamekhorshid, A., Sadrameli, S. M., \& Farid, M. (2014). A review of microencapsulation methods of phase change materials (PCMs) as a thermal energy storage (TES) medium. Renewable and Sustainable Energy Reviews, 31, 531-542.

5. Tyagi, V. V., Kaushik, S. C., Tyagi, S. K., \& Akiyama, T. (2011). Development of phase change materials based microencapsulated technology for buildings: a review. Renewable and sustainable energy reviews, 15(2), 1373-1391.

6. Ling, Z., Zhang, Z., Shi, G., Fang, X., Wang, L., Gao, X., \& Liu, X. (2014). Review on thermal management systems using phase change materials for electronic components, Li-ion batteries and photovoltaic modules. Renewable and Sustainable Energy Reviews, 31, 427-438.

7. Akbar-Khanzadeh, F., Bisesi, M. S., \& Rivas, R. D. (1995). Comfort of personal protective equipment. Applied ergonomics, 26(3), 195- 198.

8. Airaksinen, M., Tuomaala, P., \& Holopainen, R. (2007). Modeling human thermal comfort. In Proceedings of Clima(Vol. 2007, pp.10-4).

9. Hsu, Y. L., Tai, C. Y., \& Chen, T. C. (2000). Improving thermal properties of industrial safety helmets. International Journal of Industrial Ergonomics, 26(1), 109-117.

10. Hachimi-Idrissi, S., Corne, L., Ebinger, G., Michotte, Y., \& Huyghens, L. (2001). Mild hypothermia induced by a helmet device: a clinical feasibility study. Resuscitation, 51(3), 275-281.

11. Tan, F. L., \& Fok, S. C. (2006). Cooling of helmet with phase change material. Applied Thermal Engineering, 26(17-18), 2067-2072.

12. Zuo, J., Li, W., \& Weng, L. (2011). Thermal properties of lauric acid/1-tetradecanol binary system for energy storage. Applied Thermal Engineering, 31(6-7), 1352-1355.

13. Fok, S. C., Tan, F. L., \& Sua, C. C. (2011). Experimental investigations on the cooling of a motorcycle helmet with phase change material (PCM). Thermal Science, 15(3), 807-816.

14. Tan, F. L., \& Fok, S. C. (2006). Cooling of helmet with phase change material. Applied Thermal Engineering, 26(17-18), 2067-2072.

\section{AUTHORS PROFILE}

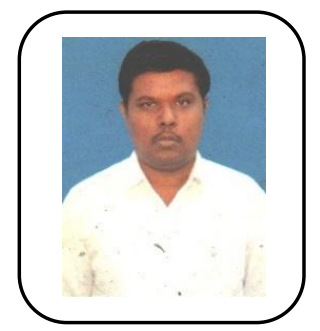

K. Vijayrakesh, graduated from the Anna University in the year 2009 with Bachelor of Engineering (Mechatronics Engineering) and Masters (Thermal) from Anna University in the year 2013. He has industrial experience in automation at Access automation pvt.ltd.

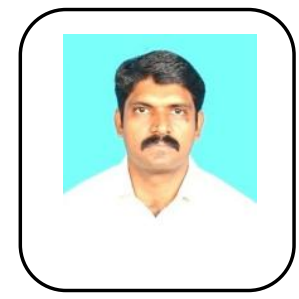

Dr. S. Muthuvel graduated from the Madurai Kamarajor University in the year 2000 with Bachelor of Engineering (Mechanical Engineering) and Masters from National Insititute of Technology in the year 2005. He has four years of industrial experience in Tata consultancy engineering. He was member of ISTE. His expertise is thermal engineering and Passive cooling applications. 